\title{
Numerical study of the induction heating of aluminium sheets for hot stamping
}

\author{
Yankang Tian ${ }^{1}$, Libo Wang ${ }^{2}$, Gerald Anyasodor ${ }^{1}$ and Yi Qin ${ }^{1, *}$ \\ ${ }^{1}$ Centre for Precision Manufacturing, Department of DMEM, The University of Strathclyde, Glasgow, G1 1XJ, UK \\ ${ }^{2}$ School of Manufacturing Sciences and Engineering, Sichuan University, Chengdu, Sichuan, China \\ * Corresponding author: qin.yi@strath.ac.uk
}

\begin{abstract}
Induction heating is one of the most popular metal heating technologies because of its high heating rate and high energy efficiency. This method is suitable for heating workpieces/blanks in different shapes, sizes and materials. Induction heating of metal sheets has been investigated by various research organizations and industrial companies. However, information concerning the induction heating of aluminium blanks is limited. Further, investigations were required by industries to address the issues relating to the uneven temperature distributions developed in the metal sheets so that an optimized design could be developed to help the enhancement of the technology. Aiming at the study of the induction heating process for hot stamping, especially the temperature distribution developed in the aluminium sheets, this paper presents in-depth analysis of induction heating using 3D FE simulations, involving uses of DEFORM and COMSOL. Different coil arrangements, level of powers, frequencies, cycle times, etc. have been modelled and simulated to examine their effects on the heating efficiency and developed temperature profiles in the Aluminium sheets. It is revealed from the simulations that design features in the induction coils like shapes of cross-sections and angles of coil corners affect the uniformity of the developed temperatures in the metal sheets. Heating with an optimized combination of the coil design and the power setting could help to achieve higher heating rates and temperature uniformity. Nevertheless, the application could be constrained by some practical factors.
\end{abstract}

Keywords: Hot stamping, Temperature, Simulation

\section{Introduction}

In a hot stamping process, a blank is heated up to a desired temperature before being transferred to the press and then formed. During the last decade, due to dramatic development of the automotive industry, demand for hot stamping of high strength material has been increasing, which also raises new requirements for the heating process. In order to enable the hot stamping process for various applications, several metal-blanks heating technologies have been developed and used in industry.

Convection furnace heating is the most commonly used heating method due to its simplicity and ease for handling metal sheets of different materials, shapes, and sizes. Moreover, the temperature of the blank can be controlled and held very easily, and it is suitable for mass production. Nevertheless, a convection heating process usually has a very low heating rate and requires a longer cycle time. A furnace system which needs to be warmed up before production usually has low energy efficiency.

Resistance heating is another popular metal-blank heating method with high heating rates, high energy efficiency, and it is cost effective. The process may require the blanks to have regular shapes and even thicknesses. Temperature uniformity of the workpiece depends largely on the geometry of the blanks and where the electrodes are applied.

A method based on induction heating may have a good balance between process flexibility and energy efficiency [1]-[3]. A wide range of materials can be heated up by the induction heating method while a fast heating rate can be achieved. Metal sheets in different shapes and sizes can be heated by induction heating. This method is energy efficient since the heat is generated from inside the workpiece. Induction heating has already been widely used for surface heat treatment minimizing heat treatment distortion and obtaining favourable compressive residual stresses [1], [2], [4]. 
Induction heating uses an alternating electromagnetic field to heat the electrically conductive materials without physical contacts [5], [6]. The material is heated up due to Faraday's law. Temperature distribution in the workpiece and the heating rate induced by induction heating are determined mainly by the workpiece material, coil design, power of the alternating current and other electrical parameters. Induction heating of metal sheets has been investigated by various research institutions and industrial companies. However, information concerning the induction heating of Al-alloy blanks for hot stamping is limited. Further, investigations were required by industries to address the issues relating to the uneven temperature distributions developed in the metal sheets so that an optimized design could be developed to help enhancing the technology.

A series of numerical simulations have, therefore, been conducted to study the induction heating process with reference to different kinds of setups and heating parameters. In this paper, the models developed will be described firstly, followed by presenting the numeric results. The focus is on the factors that influence inhomogeneous temperature distributions in the blanks and possible methods for reducing the temperature differences in the blanks. Several recommendations on deploying induction heating for aluminium-sheet hot stamping applications will also be given.

\section{Models for the numerical study of induction heating}

Induction heating of Al-alloy blanks was studied using 3D simulations. The numerical studies involved simulating heating processes with different coil shapes/sizes, positioning, blank sizes, power parameters, as well as motions of the blanks. This section describes material properties and set-ups for the numerical models.

\subsection{Material properties}

Table 1 Material Properties

\begin{tabular}{|c|c|c|c|c|}
\hline \multirow{4}{*}{ Parts } & Material & $\begin{array}{c}\text { Specific } \\
\text { Heat } \\
\text { Capacity } \\
\mathbf{U} / \mathbf{k g} \cdot \\
\boldsymbol{k})\end{array}$ & Emissivity & $\begin{array}{c}\text { Electrical } \\
\text { Resistivity } \\
(\boldsymbol{\Omega} \cdot \mathrm{m})\end{array}$ \\
\hline Blank & Al-alloy & 935 & 0.75 & $3.8 \mathrm{e}-05$ \\
\hline Coil & Copper & 386 & 1 & $1.67 \mathrm{e}-05$ \\
\hline
\end{tabular}

Table 2 Temperature-dependent behaviour of Al-alloy

\begin{tabular}{|c|c|c|c|c|c|}
\hline \multicolumn{7}{|c|}{ Al-alloy sheet } \\
\hline \multirow{3}{*}{$\mathrm{T}\left({ }^{\circ} \mathrm{c}\right)$} & $\begin{array}{c}\text { Thermal } \\
\text { Expan- } \\
\text { sion }\end{array}$ & $\mathrm{T}\left({ }^{\circ} \mathrm{C}\right)$ & $\begin{array}{c}\text { Thermal } \\
\text { Conduc- } \\
\text { tivity } \\
(\mathrm{W} / \mathrm{m} \cdot \\
\mathrm{K})\end{array}$ & $\begin{array}{c}\mathrm{T} \\
\left({ }^{\circ} \mathrm{C}\right)\end{array}$ & $\begin{array}{c}\text { Mass } \\
\text { Density } \\
(\mathrm{kg} / \\
\left.\mathrm{m}^{3}\right)\end{array}$ \\
\hline 20 & $2.18 \mathrm{e}-05$ & 50 & 280 & 20 & 2697.5 \\
\hline 200 & $2.18 \mathrm{e}-05$ & 100 & 220 & 250 & 2697.5 \\
\hline
\end{tabular}

\begin{tabular}{|l|l|l|l|l|l|}
\hline 250 & $2.21 \mathrm{e}-05$ & 150 & 200 & 300 & 2687.5 \\
\hline 300 & $2.26 \mathrm{e}-05$ & 200 & 200 & 350 & 2677.5 \\
\hline 350 & $2.32 \mathrm{e}-05$ & 250 & 200 & 400 & 2667.5 \\
\hline 400 & $2.37 \mathrm{e}-05$ & 300 & 200 & 450 & 2657.5 \\
\hline 450 & $2.42 \mathrm{e}-05$ & 600 & 200 & 500 & 2647.5 \\
\hline 500 & $2.48 \mathrm{e}-05$ & & & 550 & 2637.5 \\
\hline 550 & $2.51 \mathrm{e}-05$ & & & 600 & 2632.5 \\
\hline 600 & $2.56 \mathrm{e}-05$ & & & 700 & 2632.5 \\
\hline
\end{tabular}

Table 1 gives the material properties of the workpiece and coil used in the simulations of induction heating. Thermal expansion, thermal conductivity and mass density of aluminium alloy were considered as temperature-dependent properties and are listed in Table 2. Material properties were kept to be consistent in all simulations.

\subsection{Design of induction coil}

The designs of the induction coils in this study involved design of the cross-section shapes and arrangement of coils used for induction heating.

Cross-section shape of an induction coil is a very important design aspect. It needs to be considered carefully during the design of an induction heating process. Due to the electrical resistance of the coil material, heat is generated when high electric current is passing through the coil. If no cooling is deployed, the temperature in the coil will increase continuously. Circulated water cooling is usually adopted for transferring the generated heat away and hence, reducing the temperature in the coil.

When an alternative current is applied on a cylindrical conductor, the highest current density is observed at the inner side of the conductor [7]. This phenomenon should be considered when choosing the suitable cross-section shape for the induction coil. For induction heating of a cylindrical surface, cylindrical coil design can take the advantage of such phenomenon. While for induction heating of a metal sheet, a coil with rectangular cross-section can be placed closer to the specimen and generate more even eddy current and heating [7].

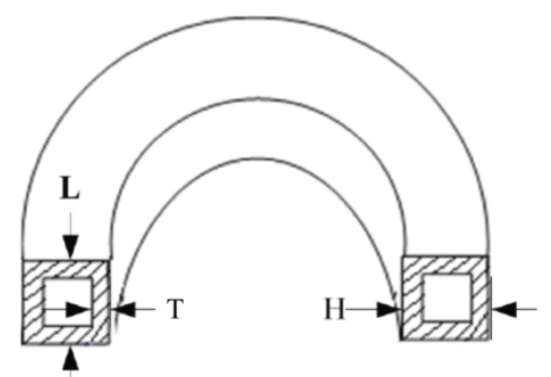

Figure 1 Cross-section of induction coil

The induction coil with hollow rectangular crosssection is chosen in this study for induction heating of shaped aluminium-alloy blanks. As shown in Figure 1, the length $\mathrm{L}$, height $\mathrm{H}$ and wall thickness $\mathrm{T}$ are three key-parameters for the coil design. Cold water flows 
through the channel inside the coil for cooling. Size of the channel influences the flow rate of cooling water.

Wall thickness of the coil was chosen to be 1.2 times of the effective skin-depth $\delta$. The effective skin-depth for copper coil was $\delta=1.53 \mathrm{~mm}$ and $\delta=0.78 \mathrm{~mm}$ respectively, when the applied power frequencies were $1800 \mathrm{~Hz}$ and $7000 \mathrm{~Hz}$. The design wall thickness T was chosen as $2.0 \mathrm{~mm}$. Based on the requirement for heating power, design length $\mathrm{L}$ and height $\mathrm{H}$ were both chosen to be $8 \mathrm{~mm}$.

Two different coil arrangements, namely longitudinal flux induction heating (LFH) and transverse flux induction heating (TFH), as shown in Figure 2, were considered for induction heating of shaped Al-alloy sheets. Performance of these two designs was evaluated by using coupled electromagnetic-thermal simulations.

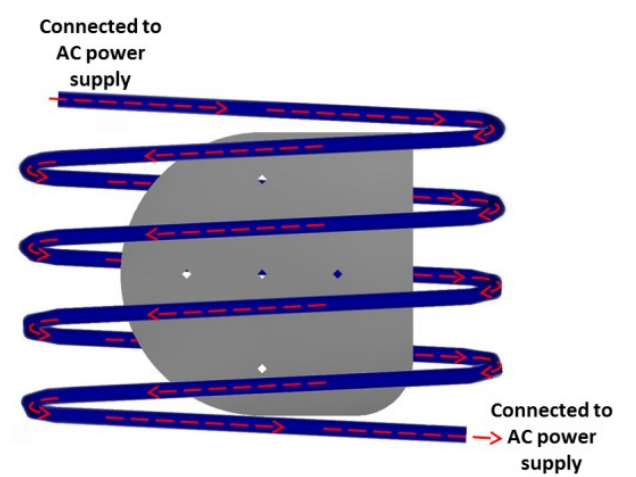

Longitudinal flux induction heating (LFH)

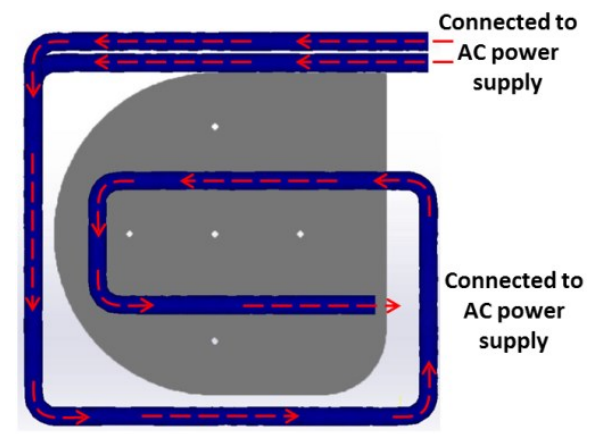

Transverse flux induction heating (TFH)

Figure 2 Two coil arrangements

\subsection{Induction heating of blanks in different sizes}

Induction heating of Al-alloy blanks in different sizes and shapes were studied numerically. Figure 3 shows the geometry of the shaped Al-alloy blank used for induction heating. Shape of the blank is not regular and it has several holes in it.

Induction heating of Al-alloy blanks of $400 \mathrm{~mm} \times$ $600 \mathrm{~mm} \times 2 \mathrm{~mm}$ was also studied with FE simulations. Two different induction heating methods were considered. One was to use a stationary coil and a moving blank which meets the workpiece from one end firstly. Coils with different shapes of corners were used in the simulations to study the effect of coil shapes. These simulations were conducted with Finite Element
(FE) software DEFORM. This software can be used to solve coupled electromagnetic - thermal problems. Figure 4 shows the engineering drawing used in these models for simulations.
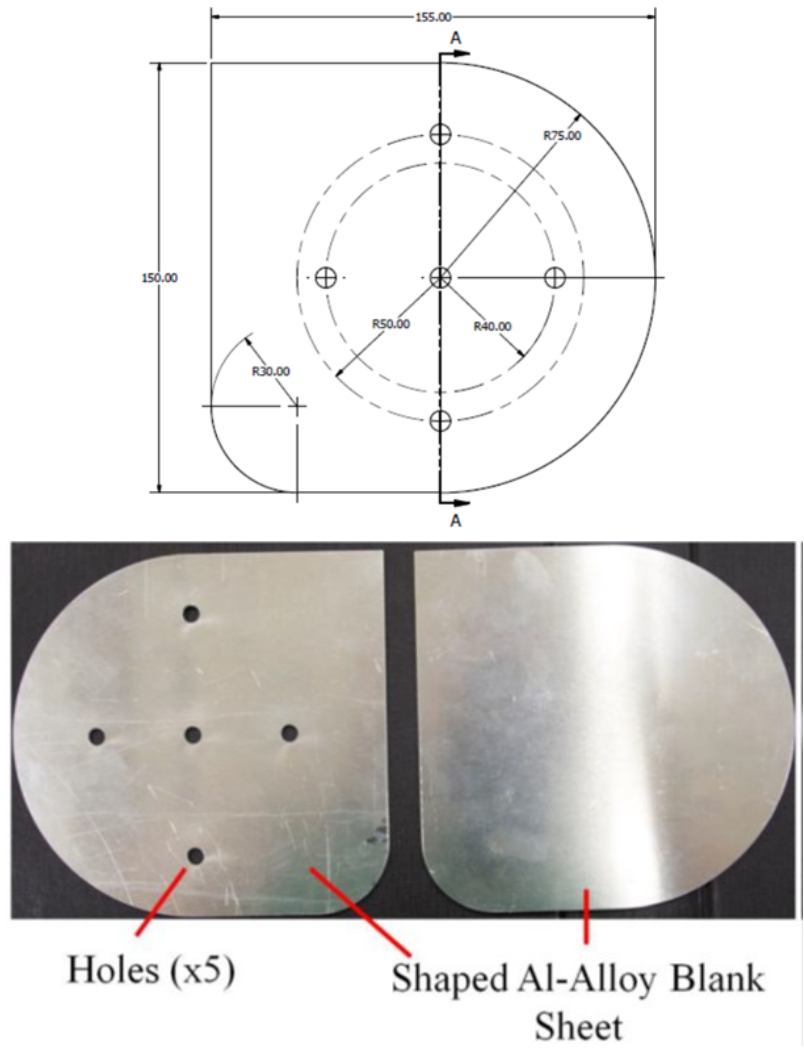

Figure 3 Geometry of small-sized Al-alloy blank
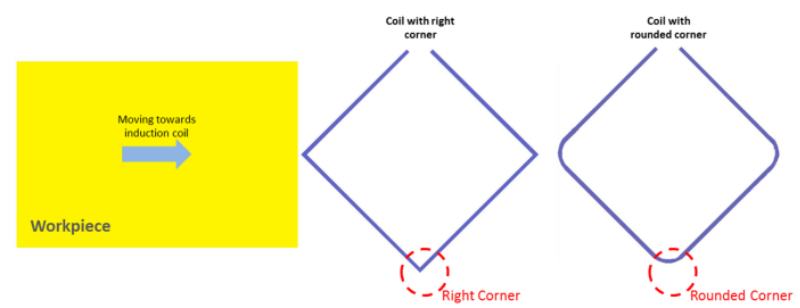

Figure 4 Model of induction heating with motion on the blank

After the investigation into shape effect of the coil, an improved design of the induction coil was developed and the heating performance of this design was also evaluated. Figure 5 shows the geometry of an improved induction coil design.

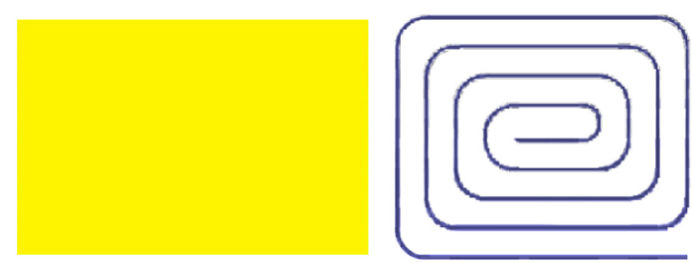

Figure 5 Induction heating with alternative coil design

The 2nd method used stationary blank and arrangement of induction coils which cover the surfaced 
area of the workpiece. Parametric simulations of different power frequencies were conducted using $\mathrm{FE}$ software COMSOL Multiphysics. AC/DC module of the software was used to study induction heating process. Eddy currents and heat transfer were coupled in this model. 3D model presented at Figure 6 illustrates the arrangement of coils and workpiece used for the parametric simulations. The workpiece was placed in the middle between the upper and lower coil sets. Table 3 lists the details of conducted simulations in this study.

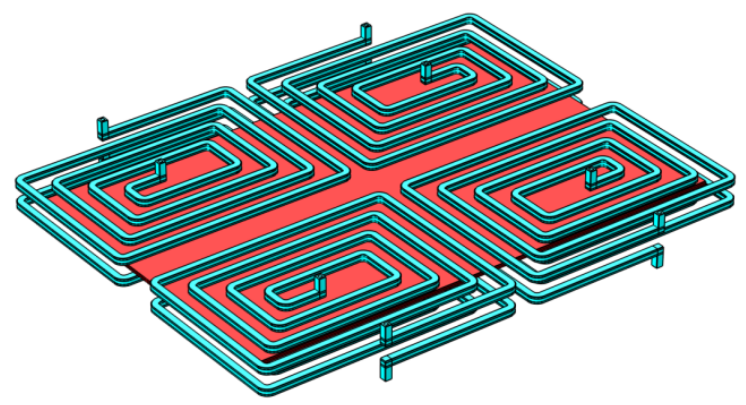

Figure 6 Model of induction heating with coil arrangement

Table 3 List of details of conducted simulations

\begin{tabular}{|c|c|c|c|c|c|}
\hline No. & $\begin{array}{c}\text { Blank } \\
\text { Size }\end{array}$ & $\begin{array}{c}\text { Coil } \\
\text { Feature }\end{array}$ & $\begin{array}{c}\text { Current } \\
\text { Density } \\
\left(\mathrm{A} / \mathrm{mm}^{2}\right)\end{array}$ & $\begin{array}{c}\text { Current } \\
\text { Frequency } \\
(\mathrm{Hz})\end{array}$ & $\begin{array}{c}\text { Blank } \\
\text { Mo- } \\
\text { tion } \\
(\mathrm{mm} / \\
\mathrm{Sm})\end{array}$ \\
\hline 1 & Small & $\begin{array}{c}\text { Trans- } \\
\text { verse } \\
(\text { LFH })\end{array}$ & 54 & 5000 & $\mathrm{~N} / \mathrm{A}$ \\
\hline 3 & Small & $\begin{array}{c}\text { Longitu- } \\
\text { dinal } \\
(\mathrm{TFH})\end{array}$ & 54 & 5000 & $\mathrm{~N} / \mathrm{A}$ \\
\hline 5 & $\begin{array}{c}\mathrm{TFH}, \\
\text { right } \\
\text { corner }\end{array}$ & 14 & 2000 & 50 \\
\hline 6 & Large & $\begin{array}{c}\mathrm{TFH}, \\
\text { rounded } \\
\text { corner }\end{array}$ & 14 & 2000 & 50 \\
\hline $\begin{array}{c}\mathrm{TFH}, \\
\text { rounded } \\
\text { corner }\end{array}$ & $\begin{array}{c}\mathrm{TFH}, \\
\text { rounded } \\
\text { corner }\end{array}$ & 27 & 5000,1000 & N/A \\
\hline
\end{tabular}

\section{Results}

\subsection{Induction heating of small Al-alloy blanks (Simulation No. 1 and No. 2)}

Figure 7 shows the temperature in the Al-alloy sheet in a transverse flux induction heating. TFH induction heating is highly efficient. Within 8 seconds after the heating started, the maximum nodal temperature reached $525.0^{\circ} \mathrm{C}$. However, severe edge effect was observed. From the beginning of the heating process, temperature at the centre of the sheet was always lower than the temperature at the edge. Higher current density occurred near the edge of the workpiece. Temperature rises at the edge area was joule heating caused by the eddy current while the temperature increment at the sheet centre was contributed by weak induction heating and thermal conduction. Temperature difference in the workpiece induced by the edge effect reaches as high as $470.0{ }^{\circ} \mathrm{C}$ at 7 second.
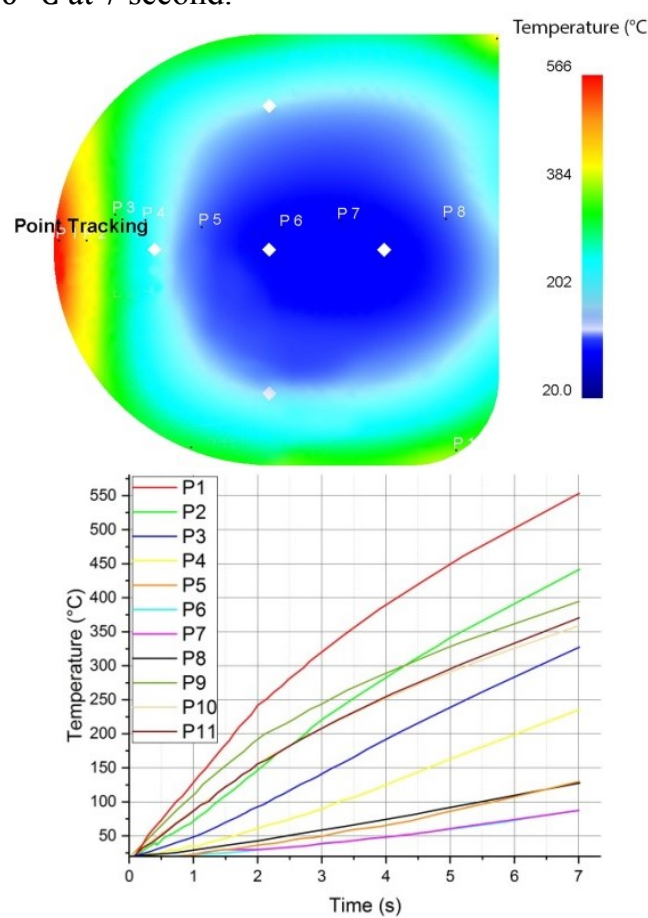

Figure 7 Temperature distribution using transverse flux induction heating in 8 seconds (simulation No. 1)
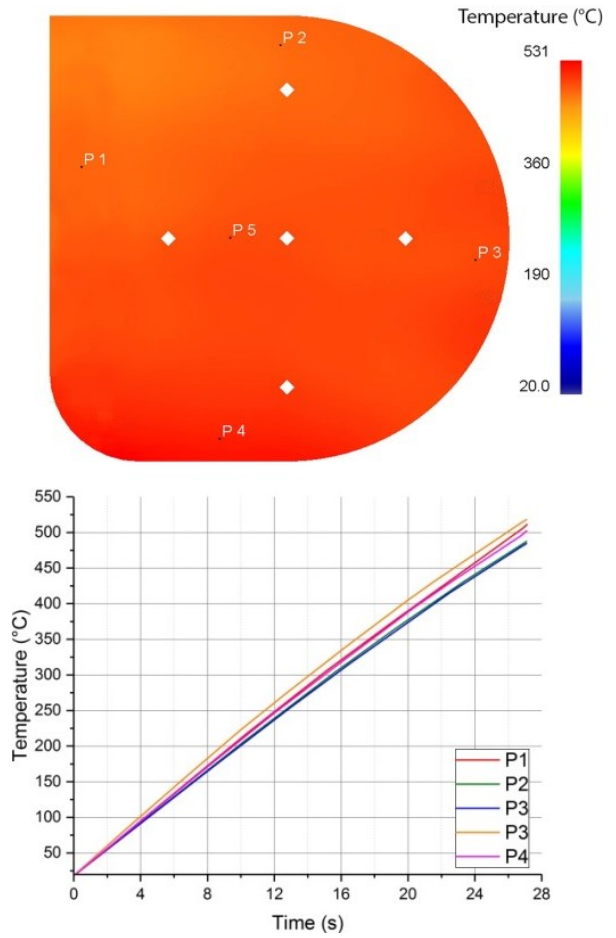
Figure 8 Comparison of induction heating with LFH and TFH methods

A similar simulation process was applied to the longitudinal induction heating model and the final numerical result of the temperature distribution is plotted in Figure 8. This result shows that within 27 seconds after the power was applied, part of the workpiece reached $525.0^{\circ} \mathrm{C}$. Without seeing severe edge effect, temperature was distributed more evenly across the whole workpiece and the highest temperature occurs at the round corner. The greatest temperature difference in the workpiece is about $50.0^{\circ} \mathrm{C}$. However, heating efficiency with this coil design is relatively low.

\subsection{Induction heating of large Al-alloy blanks with motion (Simulation No. 3, No. 4, and No. 5)}

Figure 9 shows the change of temperature in the Al-alloy sheet when it passed through the induction coil. The sheet was designed to move continuously but the simulation calculated the generated heat based on the relative position of coil and workpiece at each time step. However, the numerical results can still reveal uneven temperature distribution on the workpiece induced by edge effect. Area with relatively high temperature in the sheet had a similar shape of the coil and moved in a direction opposite to the movement of the sheet. The highest temperature was observed at the long edges, especially at each corner of the sheet. High heating rate occurred in these areas were on the account of edge effect where the coil stretched outside the sheet and led to high eddy current density. Temperature at the centre of the sheet was generally lower.

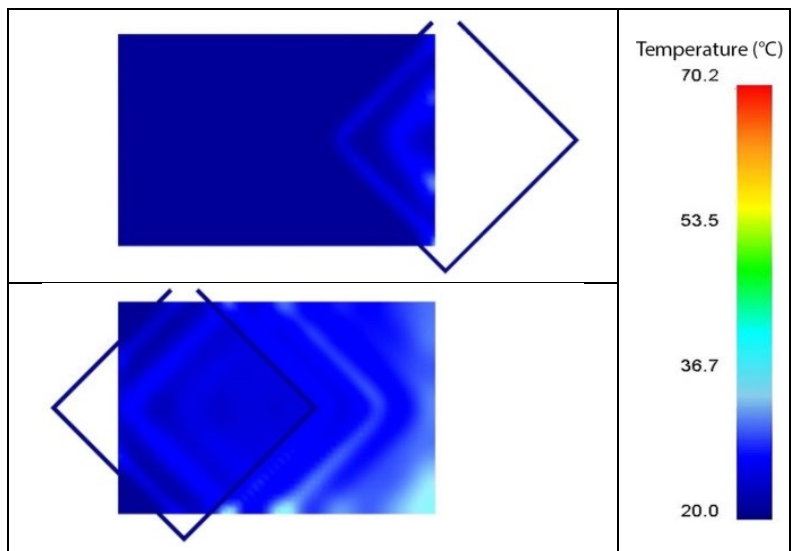

Figure 9 Numerical result of the inductive heating process with coil with right corner (Simulation No. 3)

Figure 10 presents the numerical results of induction heating which used coil with rounded corners. Although the induction edge effect in the Al-alloy sheet could still be clearly observed, more of the area in the centre of the sheet was heated up by this coil design. Coil with rounded corners has the quality to produce more even temperature distribution in the workpiece in an induction heating process.

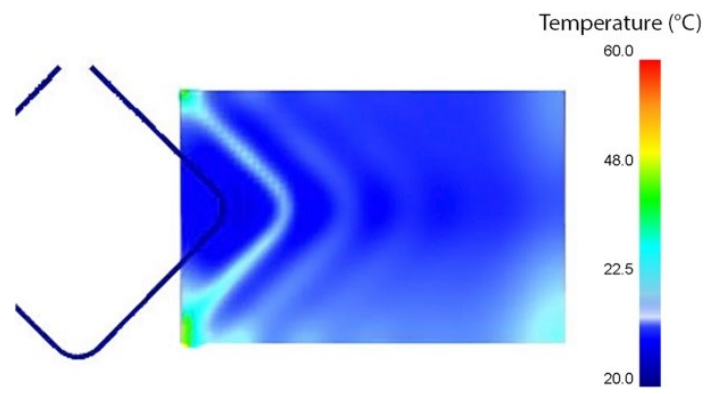

Figure 10 Temperature distribution of the inductive heating process with coil with rounded corner (Simulation No. 4)

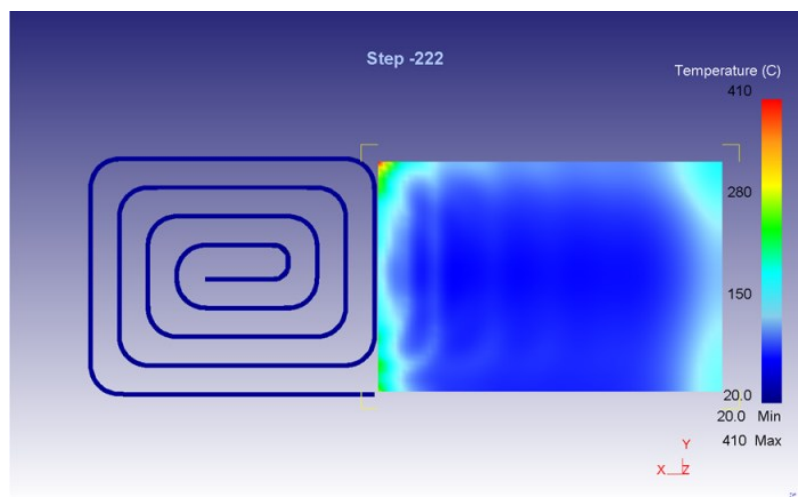

Figure 11 Simulation result of the inductive heating process with optimized induction coil design (Simulation No. 5)

After the study of cross-sections of the induction coils, coil designs and edge effect, an alternative induction coil design was proposed. Figure 11 presents the results of the numerical study of this coil design. The results show that the proposed coil design has the potential to produce more even temperature distribution pattern in the workpiece. Data reading from the simulation result also suggests that temperature in the $\mathrm{AL}$-sheet can increase by as high as $45.0^{\circ} \mathrm{C}$ in one second.

\subsection{Induction heating of large Al-alloy blanks with array of coils (Simulation No. 6)}

The second induction heating method adopted in the numerical study was use of coil arrays. For heating Alalloy blank of $400.0 \mathrm{~mm} \times 600.0 \mathrm{~mm} \times 2.0 \mathrm{~mm}$, a total of 8 induction coils were used.

In order to study the effect of alternating current frequencies on the temperature development of induction heating, the induction coils were energized by alternating currents of different frequencies. Temperature distributions on the workpiece are plotted at Figure 12.

From the results of different current frequencies, edge effect can be clearly observed. All these simulations were conducted using the current density of $27.0 \mathrm{~A} / \mathrm{mm}^{\wedge} 2$. As the frequency of the power supply 
increased, the edge effect became more obvious. For all the simulations, the edges of the workpiece were firstly heated up while the centre of the blank was still relatively cool. At $40 \mathrm{~s}$ after the heating processes started, the hottest part of the blank had a temperature above $525.0^{\circ} \mathrm{C}$ but the coolest part was still below $150.0^{\circ} \mathrm{C}$. The highest temperature on the blank is severely affected by the supply frequency. The temperature difference in the workpieces increases with increasing current frequency.

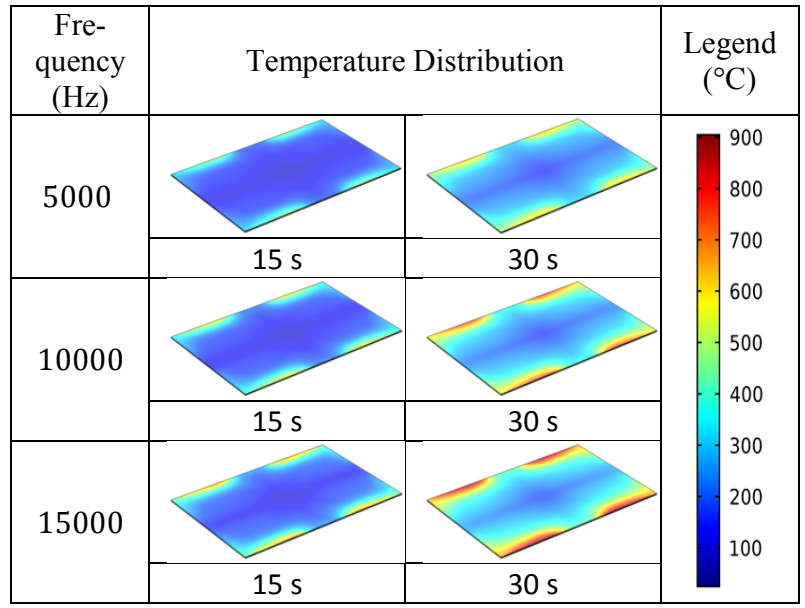

Figure 12 Temperature distribution on workpiece at different current frequencies

\section{Conclusions}

This study aims to examine the induction heating of aluminium blank for hot stamping applications. Numerical simulations were conducted to investigate effects of the coil designs and power parameters on the induction heating processes for Al-alloy blanks. Aspects like coil design selection, edge effect in induction heating, corner shape of the coil, blank movement, and current properties, etc. were considered and studied. Main conclusions from this study are as follows:

- Both TFH and LFH induction heating process were studied numerically. The TFH heating process can achieve high heating rates, being caused by the induction edge effect. The edge effect also causes the metal sheet to be heated up unevenly. LFH heating method can reduce the edge effect. However, this method is only feasible for small blanks in practise.

- Coils with sharp corners and rounded corners were both used for induction heating study for moving blank and the numerical results show that the coil with rounded corners is likely to result in more uniform heating.

- An alternative coil design was proposed for the heating of large Al-alloy sheets and a numerical simulation showed its potential to produce quick and relatively more uniform heating.

- Induction heating with coil arrays was also studied. Parametric simulations were conducted for different supplied current frequencies. The results suggest that, to obtain relatively more even temperature distribution on Aluminium sheets with thickness of $2 \mathrm{~mm}$, current with low alternating frequency is more applicable.

To adopt induction heating of aluminium blanks in hot stamping production, in practice, special attention should be paid to the selection of the coil design, suitable heating method, blank geometry and its movement, and power control. Only with "optimal" combinations of these factors/parameters, the aluminium blank could be heated up to acceptable temperatures and distributions with desired heating rates, which would help to achieve high-quality hot stamping.

\section{References}

[1] L. Jakubovičová, G. Andrej, K. Peter, and S. Milan, "Optimization of the induction heating process in order to achieve uniform surface temperature,” Procedia Eng., vol. 136, pp. 125-131, 2016.

[2] S. Klonk, "Numerical modelling of induction heating for complex geometrical parts," 2014.

[3] M. W. Kennedy, S. Akhtar, J. A. Bakken, and R. E. Aune, "Review of Classical Design Methods As Applied To Aluminum Billet Heating With Induction Coils," pp. 707-722, 2011.

[4] B. J. Yang, A. Hattiangadi, W. Z. Li, G. F. Zhou, and T. E. McGreevy, "Simulation of steel microstructure evolution during induction heating,” Mater. Sci. Eng. A, vol. 527, no. 12, pp. 2978-2984, 2010.

[5] A. Bermúdez, D. Gómez, M. C. Muñiz, and P. Salgado, "Transient numerical simulation of a thermoelectrical problem in cylindrical induction heating furnaces," Adv. Comput. Math., vol. 26, no. 1-3, pp. 39-62, 2007.

[6] D. Istardi and A. Triwinarko, "Induction Heating Process Design Using COMSOL ® Multiphysics Software," vol. 9, no. 2, pp. 327-334, 2011. 